Review

\title{
Extending the Influence of Scenario Development in Sustainability Planning and Strategy
}

\section{Peter R. Mulvihill * and Victoria Kramkowski}

Faculty of Environmental Studies, York University, 4700 Keele Street, Toronto, Ontario M3J 1P3, Canada; E-Mail: epner@yorku.ca

* Author to whom correspondence should be addressed; E-Mail: prm@ yorku.ca; Tel.: +1-416-736-2100, Ext. 22634; Fax: +1-416-736-5679.

Received: 24 June 2010; in revised form: 15 July 2010 / Accepted: 21 July 2010 / Published: 30 July 2010

\begin{abstract}
There is wide agreement that a transition toward deeper forms of sustainability would require transformational changes at many levels, transcending current patterns of incremental progress. Transformational changes might only occur, in many instances, over time frames that extend well beyond those of mainstream approaches to planning. The need for more explicit attention to longer term futures is reflected in the increasing use of scenario-based processes applied to sustainability challenges. The full potential of scenario development remains, however, largely untapped; many audiences have yet to be engaged, intrigued and influenced by them. This review article explores key barriers to more effective use of scenario development in relation to sustainability challenges, including: (1) the persistent predictive orientation of sustainability planning exercises; (2) the relatively low level of interest in weak signals and their implications; (3) institutionalized aversion to long term planning; and (4) the predominance of an essentialist perspective.
\end{abstract}

Keywords: scenarios; scenario development; scenario building in support of sustainability strategy (SBSS); weak signals; essentialism

\section{Introduction}

There is considerable agreement that if accelerated progress is to be made toward deeper forms of sustainability, new approaches to management, planning and strategy are needed [1-5]. While definitions and measures of ecological, economic and social sustainability and their interrelationship 
remain contentious, there is nonetheless a wide and increasing array of activity in many realms and sectors that refers in one way or another to sustainability as an overarching goal. Arguments are commonly made that sustainability challenges cannot be addressed effectively enough with conventional approaches to policy and planning. Myers and Kitsuse, for example, argue that a more explicit orientation toward the future is required: "Also absent from planners' approach to the future is a systemic understanding of how multiple trends will extend forward and interact with one another, shaping new possibilities and patterns of behavior in the process." [5] Rotmans et al. also argue that a new conception of planning is needed: "Such tools are needed on the interface between the short-term and the long-term, the objective and the value-laden, the quantitative and qualitative, and the certain and uncertain" [6].

The prospect of sustainability involves a largely uncharted set of complex futures and its pursuit requires a great deal of experimentation and innovation. The field of futures studies has made a substantial contribution in this regard - its literature includes frequent references to tools that may support sustainability planning and strategy, such as visioning [7,8], backcasting $[1,3,4,9,10]$ and scenario building or development [2,5,11-14], in addition to hybrid approaches that combine these and other tools. In this article we focus on scenario development and explore its potential contribution to sustainability strategy (for the sake of abbreviation, we refer to this as scenario building in support of sustainability strategy, or SBSS). Our overall impression-judging from the somewhat limited literature that pertains to SBSS - is that its potential remains largely untapped, even though scenarios are clearly intriguing to various audiences. Given the still underdeveloped potential of SBSS, our main purpose is to examine the recurring barriers that seem to prevent its wider application.

There is no definitive way to distinguish an SBSS exercise from other scenario processes which may also address aspects of sustainability. Nevertheless, when we discuss SBSS in this article we refer to the use of scenarios in relation to:

- Global or international strategies that address the challenge of sustainability; or

- Sustainability strategy or planning processes undertaken at community, regional or national levels, in the public interest.

When we think of SBSS, we have the following criteria in mind:

- Sustainability is the primary or overarching theme (as opposed, for example, to a City Plan that mentions sustainability, but does not address it in any depth);

- The exercise is guided by rigorous definitions of sustainability (for example, it is long-term focused, multi-dimensional, multi-scalar). Instead of addressing only one sector (e.g., mining or transportation), it attempts to examine "the bigger picture" in an integrated fashion.

\section{General Challenges and Controversies Surrounding Scenario Development}

The evolution of scenario development as a strategy tool, including its seminal applications in military and corporate settings, has been well documented $[11,13,15]$. The literature reveals a number of definitions of scenario development (or scenario planning), but they tend to revolve around the basic descriptions offered, for example, by Schwartz, who argues that scenarios are plausible stories of the future that might unfold and can help to: “...make strategic decisions in the present that will serve all 
plausible futures" [13]. In this limited sense, and in its private sector applications, scenario development is perceived primarily as a risk management tool. In other instances, it is aimed far beyond these narrower audiences and applied toward broad societal or even global challenges, such as resolving the ecological crisis $[2,6,16,17]$. As the practice of scenario development is adapted to different problems and challenges, its methods may vary considerably, but in most cases it is possible to recognize some classic elements or principles (although even these are subject to ongoing debates). For example, much of the literature on scenario development endorses the principle that it should not be predictive, and in practice it is often antithetical to forecasting [11,13,15]. According to this principle, scenarios do not need to be probable - they merely need to be plausible and compelling. In these and many other regards, scenario development is a counter-intuitive process. Counter-intuitiveness is an asset in distinguishing scenarios from more conventional tools such as forecasting-Schwartz, for example, stresses that the purpose of scenarios is to help us prepare for what we think will not happen [13]. It is also arguable, however, that the unorthodoxy of scenario development has tended to limit its transparency and accessibility.

At this stage in the evolution of scenario development, much of the literature remains focused on its applications in the business sector. Even when the lens of business strategy is broadened to encompass environmental or corporate social responsibility objectives, the accompanying scenario-based strategies are still much narrower in scope, and feature less complexity than is the case with SBSS. This is a general gap in the literature: relatively little of it examines the latter, more complex applications of scenario development. Indeed, as Varum and Melo point out in their overview of scenario literature, relatively little of it features the environment (let alone sustainability) as an explicit theme [18].

Despite the relative lack of documentation and analysis of SBSS, there is nevertheless a recognizable and emerging literature. It can be divided generally into two categories: one stream of literature in which SBSS is a minor theme, and the other in which it is a major one. For example, in what might be generally termed "environmental management" literature, there are indications that scenario-based approaches are being incorporated increasingly into environmental assessment, planning and management exercises [19,20-23]. Some of these exercises might be relatively conventional and narrow in scope, and do not constitute SBSS. In other cases, however, the scope and scale are broader, and explicit attempts are made to differentiate the process from conventional approaches, such as in the case of some sustainability assessment exercises at regional or national levels [24]. In related literature, arguments are made for increased use of scenarios in expanded or more ambitious environmental assessment and management [25-27]. Finally, in the literature pertaining to ecological resilience, systems theory and adaptive management, many of the concepts are compatible with scenario practice (tipping points, thresholds, abrupt change, cascading effects, panarchy, poorly understood interactions, and cross-scale interaction effects) [28]. In this type of literature, references to scenario techniques are certainly not uncommon, but it should not be confused with the SBSS category, in which sustainability scenarios are given a much more central role.

Before discussing the more germane SBSS literature, it is worth noting a number of general points that have been made about scenario development, regardless of its aims and applications. In the absence of solid quantitative data, it is difficult to determine how popular (or unpopular) scenario development might be at the present time, or whether there is a strong trend toward increasing (and 
increasingly sophisticated) applications. In discussing the use of scenarios in business settings, Lindgren and Banhold [15] note that forecasts are "daily used"; visions are "relatively often used", and scenarios are "rarely used". Indeed, it does seem safe to generalize that scenarios, regardless of their context, are still far from common or mainstream. Reed et al. [29] note an increase in scenario planning activity, but a lack of comparative analyses of these experiences. Chermack et al. observe that there is a "...current lack of sound scenario planning research...", and "Efforts to evaluate scenario planning through quantitative analyses do not exist." [30] Chermack et al. also note a lack of documentation on the successes, failures of scenario planning and "...a lack of general evaluation of scenario planning practices" [30]. A limited number of articles review the experience of scenarios in the public interest realm. For example, Myers and Kitsuse [5] discuss how scenarios were used in two planning documents: the New York Regional Plan and the American Planning Association's Growing Smart Legislative Guidebook. Since the former scenarios appeared in an Appendix, and did not appear to an integral part of the planning process and provided little strategy guidance, Myers and Kitsuse concluded that: "Despite the increased exposure conferred upon scenarios by their inclusion in these official documents, however, these scenarios are largely gratuitous."[5] Rotmans et al., as a precursor to their European VISIONS exercise, reviewed and critiqued some forty European scenario exercises, finding a number of characteristic deficiencies which constrained or precluded their application to long term sustainability strategy [6].

In their useful quantitative summary of scenario literature, Varum and Melo conclude that scenario planning, at least as reflected in the increase in literature, has enjoyed a revival [18]. In summarizing decades of scenario literature, Varum and Melo note that terms such as scenario planning and strategic scenario building tend to be used interchangeably, despite their differences. They cite Godet and Roubelat [31], who noted that the term "scenario" was being "increasingly used and abused", and Bradfield et al. [32] who noted "methodological chaos" of "contradictory definitions, characteristics, principles and methodological ideas found throughout the literature" [18].

Confusion about scenarios is a common theme. Borjeson et al. argue that "scenario" is a contested term, subject to frequent misunderstanding [33]. To some extent, the confusion has been mitigated by the appearance of scenario typologies, although these are also subject to lack of consensus [34,35]. Borjeson et al. identify nine typologies in the literature, all with their respective strengths, and also propose that there are basically three general types: predictive, explorative and normative [33]. This typology is useful, and raises the question about where SBSS might fit. Ultimately, there is no definitive answer, because the respective limitations of each type of scenario lead inevitably to hybrid approaches. In general, three points can be argued: (1) when scenarios are "too predictive", they resemble forecasting; (2) when they are "too normative", they become backcasting; and (3) explorative scenarios would appear to be, for a variety of reasons which are discussed later, most well suited to SBSS. In practice, however, there is no formula for effective or optimal use of scenarios, and in each exercise, part of the challenge is to choose methods that might find a good balance of the predictive, the normative and the explorative. Distinctions between normative [36-38] and explorative scenarios are often subtle, but, in general, practitioners of the former tend to advocate particular elements of value-laden futures, while in the latter case scenario developers merely explore a range of distinct plausible futures and suspend explicit judgment regarding their desirability. Beyond this basic 
distinction, the characteristics of normative and explorative scenarios are reflected in key subjective choices made in the determination of drivers, uncertainties and storylines.

It is common in the SBSS literature for authors to stray from strict definitions and to offer their own versions of how processes such as forecasting, visioning, backcasting, and scenario development should or should not interrelate. Carlsson-Kanyama et al. argue that backcasting belongs in the "normative" category of techniques, as a "visionary mode of thinking", and one that "seeks desirable futures" [1]. Scenarios, they argue, belong in the "explorative mode". Quist and Vergragt discuss experiences with backcasting exercises, which often feature scenario approaches, but which typically diverge from basic scenario development. They refer to "normative scenarios", and hybrid approaches such as "participatory integrated assessment" [10]. Robinson discusses "second generation backcasting", a refinement of earlier approaches, with enhanced approaches to public involvement [39]. Not surprisingly, the conceptual and methodological debates surrounding the use of these tools intensify when they are extended beyond the organizational level and applied to broader societal challenges.

A limited number of highly ambitious and elaborate SBSS-related exercises have taken place. At present, these remain atypical by virtue of their broad scope and scale, as well as the considerable time and other resources involved. The Millenium Ecosystem Assessment, though it is not a strict example of SBSS, made extensive use of scenarios [16]. Other examples include the Georgia Basin study [40], the European VISIONS project [6], the work of the Intergovernmental Panel on Climate Change [41] and the United Nations Millennium Project [42]. Another recent example is the Minnesota 2050 exercise, which combined scenario visioning and participatory system dynamics modeling [43]. High profile SBSS initiatives are valuable, not only in terms of the sustainability strategies that they may inspire, but also for the methodological lessons that they may yield and the spin-off activities that they generate, including backcasting and, it is hoped, influencing mainstream policy and strategy processes.

One of the best examples of elaborate, globally-focused SBSS is the work of The Global Scenarios Group, which has published a series of reports, including Great Transition [44]. Great Transition documents a broad scenario development exercise aimed at the challenge of global sustainability. In a sense, the report has the same "feel"-perhaps deliberately so-as the succession of high profile environment and development reports that appear periodically and command considerable attention (Limits to Growth [45]; Our Common Future [46]; Caring for the Earth [47]; and Agenda 21 [48]). Great Transition is both explorative and normative: its authors declare that: "It is a work of analysis, imagination and engagement" [44]. In this report, analysis and imagination underpin the explorative development of three distinct scenarios of the world's future. The engagement objective is explicitly normative, with the authors advancing the desirable scenario ("Great Transitions") and discussing strategies. By using this dual approach, they at once adhere to the rules of classic scenario development, and then depart from them by advocating a particular future and doing some preliminary backcasting. This overall approach is highly appropriate for the monumental, global problem that the report addresses. The methodology is described and justified, and the effect is a sophisticated adaptation of scenario development. The authors do not predict that "....a values-led shift toward an alternative global vision" will happen, but they clearly hope that readers will be convinced of its necessity [44]. A key lesson, perhaps, is that sophisticated audiences may appreciate the rigor of good scenario development in all its richness, and this quality enhances the credibility of the normative parts of the exercise. If too many compromises or shortcuts are made, audiences may find scenario 
approaches less compelling. Great Transition provides a good example of scenario development that is not normative, but which may serve a normative purpose. The less desirable stories that it proposes in rich detail are an integral part of developing and understanding a more optimistic future.

Having noted the potential of ambitious SBSS exercises, we now return to the question guiding this article: why are they not more common? As noted earlier, most of the scenario activity that is documented so far has taken place at the organizational level, and the tradition of grand, societal exercises is still brief. Next, we explore some of the characteristic barriers to more extensive use of SBSS.

\section{Methodological Chaos, Disengagement and Aversion to Long Term Planning}

For a variety of reasons documented in the literature, scenarios in general sometimes fail to engage participants or audiences, but there also appear to be particular reasons why SBSS might not be engaging. In some cases, the generic drawbacks associated with scenarios might also apply to SBSS, but it is probably unwise to generalize too much in this regard. For example, in discussing why scenarios are not, as they claim, used more widely in the corporate world, Lindgren and Banhold identify four key reasons: "uncertainty in conclusions"; "counterintuitive to managerial simplicity"; "soft methods and soft answers", and too "time consuming"[15]. It is easy to see why these issues would give pause to corporate strategists who seek answers that are less uncertain, less qualitative and more accessible. But if risk management is inherently difficult for businesses, it is all the more complex for societal sustainability challenges. In this regard, the four problems that Lindgren and Banhold identify might be considerably less salient in SBSS.

Conceptual and definitional confusion, as discussed earlier, may play a strong role in dampening enthusiasm for scenario development or SBSS. Lindgren and Banhold argue that "It is clear that scenario planning is not a very well-defined field. Rather, it is a multiplicity of perspectives and methods that could be used in various contexts, in different ways and for various purposes" [15]. The prevalence of different types of scenarios (and hybrids) adds to the potential confusion. Some typologies distinguish scenarios in terms of methods, and others in terms of goals. For example, Myers and Kitsuse discuss "state" and "process" scenarios, which imply different methods, but also note that these scenarios can sometimes pursue predictive objectives, and sometimes not [5]. A more varied typology is described by Rotmans et al., who list "forecasting", "backcasting", "descriptive", "normative", "quantitative", "qualitative", "expert" and "participatory" approaches [6]. Furthermore, van Notten et al. characterize scenarios based on project goal (which may consist of exploration, decision support, or a combination of the two), process design (which may be intuitive and based on storylines and qualitative information), format (with quantitative knowledge and computer simulation, or a combination), and scenario content (which can be simple or complex) [34]. In addition to generating confusion, the many procedural and methodological choices involved may create unproductive tensions and disagreements, tempting some to opt for more cohesive exercises such as visioning. Finally, even when scenario exercises unfold smoothly, the internal choices that are made in the process may lack transparency; external audiences may not understand or appreciate the collective thought processes that are applied to discussion of drivers, trends and uncertainties, and ultimately to the scenarios that are developed. 
One might expect urban planning practitioners and planning academics to be interested in longer term futures as a matter of course, and, by extension, the potential of futures techniques such as scenarios. But, as Myers and Kitsuse argue, both tend, for different reasons, to have surprisingly little interest in long term futures [5]. They contend that academics face pressures to devalue the longer term future as a research subject due to social science's focus on historical trends rather than potential and desirable futures, and they thus tend to abandon futures studies to the realm of practitioners [5]. According to this entrenched view, the future is somehow unreal or too abstract, and not worthy of serious study, with the implication that futurists are outside the academic mainstream. Meanwhile, Myers and Kitsuse suggest that urban planners rely heavily on forecasting instead of more explorative tools because their influence and credibility would likely be compromised in official channels if they did not do so. Planners would typically encounter great difficulty in justifying strategies based on mere stories. Professional planners tend to restrict their research to temporal and spatial boundaries that fit their mandates, and this narrow focus limits their interest in longer term and global futures. The interests of futurists, Myers and Kitsuse argue, are in sharp contrast: "Freed even from the constraints of forecasts, futurists' long term horizon allows them think boldly and imaginatively about issues of global concern. Their approach to the future is fluid but abstract" [5]. The perception that planners and futurists have little in common is troubling, but nonetheless prevalent. Urban planning processes tend to focus on shorter term and smaller picture items such as zoning, whereas scenario planning is largely about the integration of a greater range of issues. Scenario planning is well suited to ambitious, collaborative, multi-scalar ventures, often led by think tanks. But the latter may be disconnected or only tangentially connected to mainstream planning and policy processes. Tonn et al., in a survey of professionals involved in bioregional planning in the Southern Appalachians, arrived at similar conclusions, noting an aversion towards long term thinking and speculation-few professionals have direct job responsibilities that address the long term, and it is risky for them to venture too much into it [49].

Other authors discuss the challenges of engaging stakeholders in participatory scenario exercises, and in communicating and disseminating scenarios. Rotmans et al., in reviewing the experience of VISIONS for a sustainable Europe, reported that: "Concerning participation it appeared difficult to recruit high-level stakeholders, both for the European and regional participatory processes, indifferent of the participatory method used. The more heterogeneous the group of participants, the more difficult to engage stakeholders" [6]. In particular, Rotmans et al. noted the challenge of dealing with "intangible" issues that arose, such as "cultural identity", "quality of life", "social cohesion" and "institutional changes", and in making these intangible issues more concrete to stakeholders [6]. Similarly, Reed et al., in their review of UK upland futures scenarios, note challenges in communicating scenarios to stakeholders [29]. They argue that these may be overcome, for example through the use of visualization techniques, but that, once again, the less tangible issues are difficult to convey: "Aspects of scenarios that can easily be represented visually (e.g., land cover change) may receive more attention from focus group participants than other aspects (such as cultural or demographic change)" [29]. They note that scenario credibility can be reduced if stakeholders perceive techniques such as "computational simulation models" as a "black box" [29]. In a similar vein, and perhaps more fundamentally, Tonn notes general resistance to the basic idea of "futures" [50], and Tonn et al., in surveying cognitive representations of the future, found that the future 'goes dark' for the average person at around ten years into the future [51]. 
Selin explores the issue of trust in relation to scenarios, and shows how difficult it can be to establish and maintain [52]. She begins by noting that there is little research that examines whether people believe scenarios, and observes that: "Since scenarios are set in the future, one cannot base a judgment of a scenario on whether or not it is right or wrong, true or false". [52] Selin argues that trust is inherently difficult to achieve with scenarios because they result from "...group process and reconciliation", and they inevitably serve certain "...political, economic or ideological ends" at the expense of others. Scenario practitioners and participants, for their parts, are "agents of trust" who may gain or lose it. Selin concludes that trust in scenarios is heavily context dependent: “...what is reliable and credible in one setting would not be convincing in another" [52]. This suggests that the elements of effective scenario planning, recognizable though they may be, are not easily transferable or replicable. In practice, these limitations and problems (or the perception of them) may dissuade people from committing time and energy to scenario development exercises.

The aforementioned VISIONS project, an integrated assessment project aimed at a Sustainable Europe, was the subject of a retrospective analysis by some of its principals [53]. This book was reviewed critically by van der Helm [54], who makes several significant points in his review, mainly concerning methodology. First, van der Helm notes a general ongoing tension among corporate scenario practitioners, with their tendency to keep scenarios simpler, and others, such as those in VISIONS, who sought to incorporate more complexity. Among other things, van der Helm argues, this tension leads to a "rather awkward research vocabulary" [54], a description that is consistent with those who have noted the methodological confusion, if not chaos, that characterizes scenario planning. But his main criticism relates to the limited transparency of the VISIONS project. He acknowledges its ambition and goal of innovation, but doubts that this has been achieved or at least shared: "As a consequence, it never becomes clear where all these innovations have led to beyond the experience itself and whether they are valuable innovations for scenario development as a whole or just contingent attempts to make things work" [54]. van der Helm also notes that the authors have neglected to discuss "...the relevance of the exercise for the non-scientist stakeholders", which reflects another concern about scenarios: to what extent do they resonate beyond the exercise itself? If their resonance is limited, this would help explain why such initiatives have not yet inspired an explosion of interest in SBSS.

Kok et al. [55] review an exercise in which sustainability scenarios from one region were adapted, with considerable success, to another region. But they note limitations: "One drawback of using existing integrated scenarios is that they can act as a straitjacket, both when downscaling and when translating these to quantitative scenarios" [55]. This points to a recurring theme in the critical literature around scenarios - the limited extent to which one exercise can inform another, almost as if each one is a unique, isolated effort. Another example of the challenge of integrating different approaches came in the Minnesota 2050 exercise-some participants had difficulty grasping the difference between quantitative models and scenarios and seemed to believe that the former, in some cases, invalidated the latter [43]. More generally, Marchais-Roubelat and Roubelat go further and question the relationship of scenarios to any kind of action: “Are scenarios carrying actor's projects or on the contrary are they disconnected from action?" [56]. Despite these complications and critiques, it should be remembered that scenarios are just stories or perhaps professionalized fiction. It is clear, however, that at least some of the negative perceptions of scenario development result from misunderstanding of its roles and limitations, which leads to unrealistic expectations. 


\subsection{The Prediction Syndrome}

In addition to the general limitations and challenges that limit the influence and profile of scenarios, a number of specific barriers must be addressed if SBSS is to achieve greater prominence. Fundamentally, the confusing or ambiguous role of prediction presents a significant challenge. Debates over the role of forecasting or prediction are a major theme in the general scenario and SBSS literature. As noted earlier, much of the literature on scenario planning begins by emphasizing that it is very different from forecasting or prediction $[13,57,58]$. Rotmans et al., citing Jungermann, note that: "Most scenarios developed in the past were dominated by engineers, economists and planners, while contributions from the social sciences have been rare. That could be an explanation for the rather dogmatic, rigid and predictive character of many scenario exercises in the past" [6]. In their review of past European scenarios they also note other problems, including lack of diversity, a tendency toward extrapolation, lack of imagination, inconsistency, and lack of transparency.

Miller describes the far-reaching influence of the "predictive tradition" in scenario development, and the accompanying tendency for people to fall back on familiar stories: “...narratives originate either in people's current (usually unexamined) expectations and preferences or in the framework of predictive modeling familiar in the social sciences. As a result, non-conventional and transformative possibilities are under-represented" [14]. This describes a syndrome in which scenarios are not only too predictive, but also too predictable. Lindgren and Banhold suggest that an overly predictive orientation can result in scenarios which consider an overly narrow range of potential uncertainties or which do not distinguish ostensible uncertainties from real ones [15]. This underlines an important point - the "prediction paradigm" can shape and constrain any of the different steps in scenario development, including the exploration of drivers, uncertainties, and trends. Similarly, van Notten et al. argue that there is a tendency among scenario practitioners to either avoid or underplay discontinuities which disrupt the unfolding of present trends into the future, partly because they may complicate or ruin what might otherwise be attractive scenarios [34].

On the other hand, some of the literature makes the case for using predictive approaches in scenario development. For example, Bryant and Lempert [59] advocate a participatory, computer-assisted approach to "scenario discovery", partly as a means to overcoming discord in scenario exercises. With this kind of approach, limits to prediction are acknowledged, but prediction is still implied as an eventual goal. Similarly, some of the literature, for example Wang and Lan [60] reflects a view that limits to scenario development might be overcome by improving the predictive aspects. This type of scenario literature makes an explicit case for prediction, and may or may not persuade potential practitioners of SBSS, particularly when longer term horizons are being addressed. However, to complicate matters, in many instances the influence of the predictive paradigm in scenario development is implicit and pervasive; if it is not acknowledged or challenged, the result can be the development of ostensible scenarios that are really forecasts. When this happens, the range of plausible futures (including alternative ones) that might be considered in strategy development is narrowed considerably. Finally, and ironically, the business-oriented literature on scenarios sometimes indicates that in cases where scenario planning has played an influential role in supporting successful strategy, it is actually mistaken for prediction. The "prescient" strategists are commended for their foresight, when in fact they were merely identifying plausible futures, and most of their "predictions" did not come 
to pass. This suggests, however, that to some extent, even when scenario development is misunderstood it can nevertheless have benefits in terms of revised strategies. Overall, however, we argue that a predominantly predictive approach is more limiting than empowering in scenario development, particularly in SBSS challenges, with their great complexity, uncertainty and imperative of transformative strategies.

\subsection{The Influence of Essentialist Perspectives}

Planning exercises aimed at transformative change in more sustainable directions require at minimum the belief that a range of different futures - some of them desirable - is possible. Participants and stakeholders may be pessimistic, and they may be deeply skeptical that prospects such as social and ecological sustainability will actually be achieved in their lifetimes. Fortunately, optimism is not a pre-requisite of scenario development or SBSS. Scenario development does, however, require the acceptance that plausible futures, no matter how improbable they seem, could actually unfold. In addition, it requires the acceptance that the future contains surprises and discontinuities. The attitude that is needed (or at least desirable) for scenario development might be described as a non-essentialist outlook - the belief that there is little, if anything, that is pre-determined about the longer-term future. In contrast, an essentialist outlook would dictate that some elements of the longer term future are inevitable, and likely unchangeable. These elements might typically include such things as war, greed, over-exploitation of natural resources, and ecological collapse. From an essentialist perspective, certain pre-determined elements are part of every future, regardless of attempts to change values or behavior. For example, Hardin's "The Tragedy of the Commons" [61] might not be regarded as a warning, but as a certainty. Needless to say, essentialism, in this sense, runs counter to the spirit and intent of scenario development, and particularly SBSS. Individuals whose perspectives and worldviews are strongly essentialist would probably be disinclined toward scenario development, and might prefer forecasting as their futurist tool of choice. A question thus arises: does the need for a sufficient degree of non-essentialism pose a significant barrier, constraining SBSS from gathering more momentum and influence?

A number of authors have discussed this aspect, both directly and indirectly. It is a significant theme for Schwartz, who discusses how people tend to "...react to uncertainty with denial" [13] and buttress their view of the future with the false security that certain disruptive or radical events will not occur. Schwarz further noted that participants from certain professions tend to struggle more than others with scenario planning because of the deterministic nature of fields such as engineering and accounting. He describes a popular type of scenario plot based on a dynamic of dominance and subservience: "This plot starts with the perception that the world is essentially limited, that resources are scarce, and that if one side gets richer, the other side must get poorer" [13]. Schwartz suggests that this overly deterministic plot takes away substantially from what might otherwise be a more creative and valuable scenario development process. Similarly, excessive belief in deterministic theories such as long economic cycles can also play a constraining role on plots, as Godet points out: "Some analysts have dusted off Kondratieff's famous long cycles in which the market economy is punctuated every 50 years, according to the rhythms of innovation..." [11]. 
At the organizational level, Wright et al. discuss and summarize the syndrome of "strategic inertia" and "strategic drift" that can plague organizations, and pose a barrier to successful engagement in scenario planning [62]. They state that the underlying causes of strategic inertia in organizations include "coping patterns of bolstering failing strategy", "procrastination" or "buck-passing". In this syndrome, organizations seem to perceive a lack of alternatives, or a pre-determined future. While the analogy may not apply seamlessly to the challenge of global sustainability, it is possible to term the slow progress in this regard as a kind of collective strategic drift.

Once again in the context of organizational experience with scenario planning, MacKay and McKiernan identify four dysfunctional tendencies which they call "creativity layered on fantasy", "heightened expectations and confusion", "pride and passion", and "creativity leading to excess" [63]. They describe a syndrome in which the initial excitement of engagement in scenario processes erodes and leads back to business as usual: "The excitement of dealing with creativity, narrative, imagination, dream and intuition soon fades once the routine tasks are taken up again. These can cause a return of the prior 'comfort zone' and its automatically triggered 'business as usual' procedure. It is tough to link scenarios to this everyday world, as they are perceived as too creative, too distant and too long into the future" [63]. MacKay and McKiernan also note the necessity of novelty or a "wow factor" in scenarios in order for them to be provocative on initial reading.

Reed et al. [29] discuss and compare eight scenario exercises that explored UK upland futures. Even though this type of problem (challenges to agriculture and rural livelihoods) is very much a sustainability challenge in the public realm, they note that public involvement was limited, stating that "Although many of the interviewees suggested that members of the general public should be involved in scenario evaluation, very few of the studies actually involved representatives from the general public" [29]. Since, in these instances, public involvement was limited at the scenario evaluation stage, one might assume that it was also limited or absent at earlier stages of the process. Reed et al. also note that when the general public was consulted, “...respondents displayed a preference for the status quo over scenarios that involved change" [29]. This is similar to the phenomenon of strategic inertia discussed by Wright et al. [62]; if the general public is not really open to different possible futures, a scenario exercise will be very much constrained. Similarly, Duinker and Greig warn about the tendency of participants or decision-makers to get attached to one "likely" or "favourite" scenario, thus negating the value and benefits that other seemingly less probable scenarios may offer to planning strategies [25]. On the other hand, it may be possible for a skillfully managed and engaging scenario process to influence participants, resulting in increased openness to alternative futures [64].

While the influence of essentialism is not an explicit theme in the scenario literature, it does appear in a variety of implicit ways, and it appears to be an omnipresent and complicated challenge for those who seek to promote scenario-based approaches. A survey conducted by Tonn et al., for example, suggests that essentialist views are strongly dependent on context: "a majority or respondents believe that they have control over their lives but a majority also believes that humanity does not have control over its future". They also found that religious views greatly influence views about the future [51]. 


\subsection{Weak Signals and Related Obscure Forces}

A number of authors [65-68] have discussed the profound influence of weak signals in shaping futures, although they often go unnoticed or are recognized too late to inform strategies. Some of the same literature discusses the influence of wild cards, although the two should not be confused (it is easier to perceive wild cards, but still difficult to predict their significance, whereas weak signals may go unnoticed entirely). The importance of detecting weak signals in scenario development is sometimes (though not always) noted. In practice, it is difficult to find good examples of scenarios or SBSS in which weak signals were instrumental in shaping storylines in either a positive or negative way. Alternately, when these scenarios are constructed, they are framed and presented as being the outlier story compared to more likely ones. This leads us to venture the generalization that weak signals tend to be under-represented in scenario processes and plots. This may be highly significant because, in retrospect, it is usually easy to see that many problems, disasters and undesirable trends were foreshadowed by weak signals that went mostly unnoticed. In other words, there is little doubt that the weak signals (along with stronger signals) of unsustainable, undesirable futures are all around us. If we are somehow able to improve our ability to detect and analyze weak signals, we may enhance our ability to alter or avoid grim futures. This is a particular potential strength of scenarios-weak signals may have little place in forecasting or mainstream planning, but scenario processes are well designed to brainstorm and probe them. The literature, however, indicates that weak signals and related obscure phenomena are typically not an integral part of scenario development. Rotmans et al. make this point explicitly: "Regrettably, many of the more influential scenarios that have been developed over the last decades did not focus on weak signals" [6].

Godet elaborates on weak signals, describing them as "factors of change which are now barely perceptible but will make up tomorrow's prevailing or megatrends. In fact a latent variable is what $\mathrm{P}$. Masse called a 'seed event, or a miniscule sign given current dimensions but immense in its virtual consequences"" [11]. Similarly, Lindgren and Banhold describe wild cards as "unlikely future events that would have great impact if they occurred. Wild cards create discontinuities in the development curve. Scenarios can be generated around wild cards, but wild cards are usually sifted out in scenario processes and treated separately" [15]. Kuosa, however, argues that the term weak signal is a "blurred concept", and their detection tends to be highly arbitrary: "Thus, 'weak signal' seems to be everything and anything that is related to substantial potential change, or can be any idea that is related to futures images, utopias, dystopias or values" [69]. Kuosa argues for a more systematic way of analyzing weak signals, but this is clearly an inherently difficult pursuit. A number of other authors also discuss the difficulties and vagaries of trying to scan for weak signals or wild cards [65-68,70]. The European Commission's iKnow project [71] provides a valuable resource to track and document weak signals. In general, weak signals and wild cards are variously characterized as virtually imperceptible, ill-defined, mundane, highly uncertain, peripheral, or not credible, thus giving a sense of the difficulty of tracking them. Schwartz also hints at the process of examining weak signals by discussing generally the challenges of recognizing signals, recommending exploration of "fringe" information, and arguing that skilled scenario planners should spend considerable time developing and refining their "filters" of potentially meaningful peripheral information [13]. 
The concept of weak signals can be linked to similar ideas such as a "tipping point" in which, as Gladwell [72] argues, seemingly trivial things can make a big difference, or "disaster incubation", in which the underlying causes of eventual disasters unfold and accumulate in largely unnoticed ways. Turner [73] identified typical factors of disaster incubation, including underlying organizational factors such as "rigidities in institutional beliefs", "the presence of decoy phenomena", and "multiple information-handling difficulties". This is consistent with challenges summarized by Kuosa, including "information overflow" and "determining relevance" [69].

Just as weak signals pertain to marginal phenomena, the concept itself is a marginal theme in the literature - a subtle and elusive subject. There is no reliable way of identifying weak signals or judging their significance. It is somewhat understandable that corporate or organizational scenario practitioners would tend to ignore or under-emphasize weak signals. It may be difficult or impossible for corporate strategists to make convincing cases for risk management strategies based on obscure forces that may turn out to be insignificant. In the realm of SBSS, there is greater risk in ignoring weak signals, because of the much greater dynamics and complexities of regional and global futures. To SBSS skeptics, however, the vagaries of weak signals are another reason to avoid or dismiss explorative scenario approaches - these signals may be presented as key elements of undesirable scenarios, and they may not even be "real" in the first place. To some, the exploration of weak signals may reinforce the air of unreality surrounding scenario development.

\section{Conclusions}

In this article we have explored barriers that may prevent greater experimentation with SBSS. It is not surprising that the tentative combination of two fledgling pursuits - sustainability planning and scenario development - is still at an early stage. Virtually everything concerning sustainability is fluid, uncertain and contested. The concept gained popularity barely a generation ago, as an attempt to contextualize and integrate a myriad of interrelated challenges surrounding the ecological crisis. As a repertoire of approaches has gradually emerged, the niche for SBSS has been created, and highlighted by global initiatives such as Great Transition, along with some notable regional efforts. It remains unclear how much this niche will expand, and it also remains to be seen which particular hybrid forms of SBSS will prove to be most popular and influential. If sustainability planning turns out to be mostly a normative pursuit, backcasting and related approaches may gain more prominence, and explorative scenarios may assume a more secondary role as background research-pre-cursors informing backcasted future plans.

For some audiences, the complicatedness of scenario development-with its non-predictive orientation, its counter-intuitive logic, its scanning for weak signals, its multiple storylines, its non-linearity, its discontinuities and its appeal to non-essentialism-is precisely what embodies its distinctive value. Perhaps the collective experience of negotiating barriers on the way to developing scenarios mirrors, in some ways, the complex, pluralistic process of compromise that could lead to more sustainable futures. Proponents of scenario development are most convincing when they point out the shorter term benefits of the process - it can generate insights that challenge prevailing assumptions, and it can lead to better questions that otherwise might not be asked. 
As noted earlier, there are useful scenario typologies that broadly distinguish prevailing approaches, which depend greatly on the context in which they are used. We have also argued that hybrid approaches that mix scenarios, visions, predictions, models and other elements are not only creative - they are common enough that it can almost be concluded that hybridization is the norm, at least in the broad, complex realm of SBSS. Scenario literature also indicates that the approaches taken are seldom obvious or pre-determined - they are negotiated and re-invented case by case. This reflects, not surprisingly, a degree of restlessness or dissatisfaction with the current repertoire of approaches. Beyond a tentative set of principles, very little is certain about sustainability, or how to plan for it in the longer term. Scenarios represent an intriguing alternative approach. There is no recipe for SBSS, but we suggest several principles, which favor an explorative approach overall while leaving room for normative elements.

- The prospect of sustainability, in many regards, is a long-term prospect, and inherently multi-scalar. This involves high levels of uncertainty, which requires a strong degree of exploration, and recognition of the limits of prediction and prescription.

- Long term transformation has both normative and explorative aspects that need to be addressed. This tends to favor hybrid approaches, which in turn requires collective choices.

- Essentialist perspectives are common in scenario exercises. In keeping with the spirit of explorative scenarios, it is necessary and appropriate to respectfully challenge the assumptions underlying essentialist views.

- In order to be sufficiently explorative, weak signals, wild cards and related phenomena should be given due attention.

- Robust strategies require robust scenarios - it is important for participants to avoid shortcuts, and construct rich stories of the future. The richness of the detail, as argued by many authors, is key to building engaging and scenarios.

The authors of Great Transition aspired to create a work of "analysis, imagination and engagement". To a great extent, these descriptors capture the essential criteria of powerful scenario development. If analysis, imagination and engagement are achieved in an SBSS exercise, they will help overcome three interrelated challenges: aversion to scenarios, limited use of SBSS, and the aforementioned methodological chaos.

\section{Acknowledgments}

The authors wish to thank the editors and referees for the many thoughtful and useful comments and suggestions.

\section{References}

1. Carlsson-Kanyama, A.; Dreborg, K.H.; Moll, H.C.; Padovan, D. Participative backcasting: A tool for involving stakeholders in local sustainability planning. Futures 2008, 40, 34-46.

2. Peterson, G.D.; Cumming, G.S.; Carpenter, S.R. Scenario planning: A tool for conservation in an uncertain world. Conserv. Biol. 2002, 17, 358-366. 
3. Holmberg, J.; Robert, K.H. Backcasting-A framework for strategic planning. Int. J. Sustain. Dev. World Ecol. 2000, 7, 291-308.

4. Robinson, J.B. Future under glass - A recipe for people who hate to predict. Futures 1990, 22, 820-842.

5. Myers, D.; Kitsuse, A. Constructing the Future in Planning: A Survey of Theories and Tools. J. Plan. Educ. Res. 2000, 19, 221-231.

6. Rotmans, J.; van Asselt, M.; Anastasi, C.; Greeuw, S.; Mellors, J.; Peters, S.; Rothman, D.; Rijkens, N. Visions for a sustainable Europe. Futures 2000, 32, 809-831.

7. Helling, A. Collaborative visioning: Proceed with caution! Results from evaluating Atlanta's Vision 2020 project. J. Am. Plann. Assoc. 1998, 64, 335-349.

8. Malaska, P.; Hostius, K. Visionary Management. Foresight 1999, 1, 353-361.

9. Dreborg, K.H. Essence of Backcasting. Futures 1996, 28, 813-828.

10. Quist, J.; Vergragt, P. Past and future of backcasting: The shift to stakeholder participation and a proposal for a methodological framework. Futures 2006, 38, 1027-1045.

11. Godet, M. Creating Futures: Scenario Planning as a Strategic Management Tool, 2nd ed.; Economica: London, UK, 2006.

12. Brewer, G.D. Inventing the future: Scenarios, imagination, mastery and control. Sustain. Sci. 2007, 2, 159-177.

13. Schwartz, P. The Art of the Long View: Planning for the Future in an Uncertain World; Currency Doubleday: New York, NY, USA, 1991.

14. Miller, R. Futures literacy: A hybrid strategic scenario method. Futures 2007, 39, 341-362.

15. Lindgren, M.; Bandhold, H. Scenario Planning: The Link between Future and Strategy; Palgrave Macmillan: London, UK, 2009.

16. Millenium Ecosystem Assessment (MEA). Ecosystems and Well-Being: A Framework for Assessment; Island Press: Washington, DC, USA, 2003.

17. Hopkins, L.D.; Zapata, M.A. Engaging the Future: Forecasts, Scenarios, Plans, and Projects; Lincoln Institute of Land Policy: Cambridge, MA, USA, 2007.

18. Varum, C.A.; Melo, C. Directions in scenario planning literature-A review of the past decades. Futures 2010, 42, 355-369.

19. Johnson, T.E.; Weaver, C.P. A Framework for Assessing Climate Change Impacts on Water and Watershed Systems. Environ. Manage. 2009, 43, 118-134.

20. Volkery, A.; Ribeiro, T.; Henrichs, T.; Hoogeveen, Y. Your Vision or My Model? Lessons from Participatory Land Use Scenario Development on a European Scale. Syst. Pract. Action Res. 2008, 21, 459-477.

21. Tompkins, E.L.; Few, R.; Brown, K. Scenario-based stakeholder engagement: Incorporating stakeholders preferences into coastal planning for climate change. J. Environ. Manage. 2008, 88, 1580-1592.

22. Lange, E.; Hehl-Lange, S.; Brewer, M.J. Scenario-visualization for the assessment of perceived green space qualities at the urban-rural fringe. J. Environ. Manage. 2008, 89, 245-256.

23. Barredo, J.I.; Englelen, G. Land Use Scenario Modeling for Flood Risk Mitigation. Sustainability 2010, 2, 1327-1344. 
24. Partidario, M.P.; Sheate, W.R.; Bina, O.; Byron, H.; Augusto, B. Sustainability Assessment for Agricultural Scenarios in Europe's Mountain Areas: Lessons from Six Study Areas. Environ. Manage. 2009, 43, 144-165.

25. Duinker, P.N.; Greig, L.A. Scenario analysis in environmental impact assessment: Improving explorations of the future. Environ. Impact. Assess. Rev. 2007, 27, 206-219.

26. Mulvihill, P.R.; Ali, S.H. Disaster incubation, cumulative impacts and the urban/ex-urban/rural dynamic. Environ. Impact. Assess. Rev. 2007, 27, 343-358.

27. Mulvihill, P.R. Expanding the scoping community. Environ. Impact. Assess. Rev. 2003, 23, 39-49.

28. Duit, A.; Galaz, V. Governance and Complexity-Emerging Issues for Governance Theory. Governance 2008, 21, 311-335.

29. Reed, M.S.; Arblaster, K.; Bullock, C.; Burton, R.J.F.; Davies, A.L.; Holden, J.; Hubacek, K.; May, R.; Mitchley, J.; Morris, J.; Nainggolan, D.; Potter, C.; Quinn, C.H.; Swales, V.; Thorp, S. Using scenarios to explore UK upland futures. Futures 2009, 41, 619-630.

30. Chermack, T.J.; Lynham S.A.; van der Merwe, L. Exploring the relationship between scenario planning and perceptions of learning organization characteristics. Futures 2006, 38, 767-777.

31. Godet, M.; Roubelat, F. Creating the future: The use and misuse of scenarios. Long Range Plann. 1996, 29, 164-171.

32. Bradfield, R.; Wright, G.; Burt, G.; Cairns, G.; Heijden, K.V.D. The origins and evolution of scenario techniques in long range business planning. Futures 2005, 37, 795-812.

33. Borjeson, L.; Hojer, M.; Dreborg, K.H.; Ekvall T.; Finnveden, G. Scenario types and techniques: Towards a user's guide. Futures 2006, 38, 723-739.

34. van Notten, P.W.F.; Sleegers, A.M.; van Asselt, M.B.A. The future shocks: On discontinuity and scenario development. Technol. Forecast. Soc. Change 2005, 72, 175-194.

35. Hirschhorn, L. Scenario writing: A developmental approach. J. Am. Plann. Assoc. 1980, 46, 172-183.

36. Kuosa, T. Future of US Power; Available online: http://www.rsis.edu.sg/publications/ WorkingPapers/WP203.pdf (accessed on 15 June 2010).

37. Coates, J.; Glenn, J.C. Normative Forecasting. In Futures Research Methodology-Version 3.0 [CD-ROM]; Glenn, J.C., Gordon, T.J., Eds.; World Federation of United Nations Associations: Washington, DC, USA, 2009.

38. Glenn, J.C.; The Futures Group International. Scenarios. In Futures Research Methodology_Version 3.0 [CD-ROM]; Glenn, J.C., Gordon, T.J., Eds.; World Federation of United Nations Associations: Washington, DC, USA, 2009.

39. Robinson, J. Future subjunctive: Backcasting as social learning. Futures 2003, 35, 839-856.

40. Tansey, J.; Carmichael, J.; Van Wynsberghe, R.; Robinson, J. The future is not what it used to be: Participatory integrated assessment in the Georgia Basin. Glob. Environ. Change 2002, 12, 97-104.

41. Climate Change 2007: Synthesis Report. Contribution of Working Groups I, II and III to the Fourth Assessment Report of the Intergovernmental Panel on Climate Change; Core Writing Team, Pachauri, R.K., Reisinger, A., Eds.; Intergovernmental Panel on Climate Change (IPCC): Geneva, Switzerland, 2007. 
42. Glenn, J.C.; Gordon, T.J.; Florescu, E. 2009 State of the Future. The Millennium Project; Global Futures Studies and Research: Washington, DC, USA, 2009.

43. Schmitt Olabisi, L.K.; Kapuscinski, A.R.; Johnson, K.; Reich, P.B.; Stenquist, B.; Draeger, K.J. Using Scenario Visioning and Participatory System Dynamics Modeling to Investigate the Future: Lessons from Minnesota 2050. Sustainability 2010, submitted.

44. Raskin, P.; Banuri, T.; Gallopin, G.; Gutman, P.; Hammond, A.; Kates, R.; Swart, R. Great Transition: The Promise and Lure of the Times Ahead; A Report of the Global Scenario Group, SEI PoleStar Series Report No. 10; Stockholm Environment Institute: Boston, MA, USA, 2002.

45. Meadows, D.H.; Randers, J.; Meadows, D.L.; Behrens, W.W. The Limits to Growth: A Report for the Club of Rome's Project on the Predicament of Mankind; Universe Books: New York, NY, USA, 1972.

46. World Commission on Environment and Development. Our Common Future; Oxford University Press: New York, NY, USA, 1987.

47. Munro, D.; Holdgate, M.W. Caring for the Earth; WCU/UNEP/WWF: Gland, Switzerland, 1991.

48. Agenda 21: Green Paths to the Future; IDRC Books: Ottawa, Canada, 1993.

49. Tonn, B.; English, M.; Turner, R.; Hemrick, A. The Future of Bioregional Planning in the Southern Appalachian Man and the Biosphere Region. Futures 2006, 38, 490-504.

50. Tonn, B. What's in a name: Reflections on Ziauddin Sardar's 'the namesake'. Futures 2010, 42, 195-198.

51. Tonn, B.; Conrad, F.; Hemrick, A. Cognitive Representations of the Future: Survey Results. Futures 2006, 38, 810-829.

52. Selin, C. Trust and the illusive force of scenarios. Futures 2006, 38, 1-14.

53. van Asselt, M.B.A.; Rotmans, J.; Rothman, D.S. Scenario Innovation: Experiences from a European Experimental Garden; Taylor \& Francis: London, UK, 2005.

54. van der Helm, R. M.B.A. van Asselt, J. Rotmans and D.S. Rothman, Scenario Innovation: Experiences from a European Experimental Garden, Taylor \& Francis, London (2005) 224pp, $£ 49.00$. Futures 2007, 39, 1134-1138.

55. Kok, K.; Rothman, D.S.; Patel, M. Multi-scale narratives from an IA perspective: Part I. European and Mediterranean scenario development. Futures 2006, 38, 261-284.

56. Marchais-Roubelat, A.; Roubelat, F. Designing action based scenarios. Futures 2008, 40, 25-33.

57. Porter, M.E. Competitive Advantage: Creating and Sustaining Superior Performance; Free Press: New York, NY, USA, 1998; pp. 557.

58. Schoemaker, P.J.H. When and how to use scenario planning-A heuristic approach with illustration. J. Forecast. 1991, 10, 549-564.

59. Bryant, B.P.; Lempert, R.J. Thinking inside the box: A participatory, computer-assisted approach to scenario discovery. Technol. Forecast. Soc. Change 2010, 77, 34-39.

60. Wang, M.Y.; Lan, W.T. Combined forecast process: Combining scenario analysis with the technological substitution model. Technol. Forecast. Soc. Change 2007, 74, 357-378.

61. Hardin, G. The Tragedy of the Commons. Science 1968, 162, 1243-1248.

62. Wright, G.; van der Heijden, K.; Burt, G.; Bradfield, R.; Cairns, G. Scenario planning interventions in organizations: An analysis of the causes of success and failure. Futures 2008, 40, 218-236. 
63. MacKay, B.; McKiernan, P. Creativity and dysfunction in strategic processes: The case of scenario planning. Futures 2010, 42, 271-281.

64. Frittaion, C.M.; Duinker, P.N.; Grant, J.L. Narratives of the future: Suspending disbelief in forest-sector scenarios. Futures 2010, in press.

65. Harris, D.; Zeisler, S. Weak signals: Detecting the next big thing. Futurist 2002, 36, 21-28.

66. Mendonca, S.; Pina e Cunha, M.; Kaivo-oja, J.; Ruff, F. Wild cards, weak signals and organizational improvisation. Futures 2004, 36, 201-218.

67. Ansoff, I. Managing strategic surprise by response to weak signals. Calif. Manage. Rev. 1975, 17, 21-33.

68. Pina e Cunha, M.; Chia, R. Using teams to avoid peripheral blindness. Long Range Plann. 2007, 40, 559-573.

69. Kuosa, T. Futures signals sense-making framework (FSSF): A start-up tool to analyse and categorise weak signals, wild cards, drivers, trends and other types of information. Futures $\mathbf{2 0 1 0}$, 42, 42-48.

70. Konnola, T.; Brummer, V.; Salo, A. Diversity in foresight: Insights from the fostering of innovation ideas. Technol. Forecast. Soc. Change 2007, 74, 608-626.

71. European Commission. The iKnow Project; Available online: http://wiwe.iknowfutures.eu (accessed on 15 June 2010).

72. Gladwell, M. The Tipping Point: How Little Things Can Make a Big Difference; Little Brown: New York, NY, USA, 2000.

73. Turner, B.A. The organizational and interorganizational development of disasters. Adm. Sci. $Q$ 1976, 21, 378-97.

(C) 2010 by the authors; licensee MDPI, Basel, Switzerland. This article is an Open Access article distributed under the terms and conditions of the Creative Commons Attribution license (http://creativecommons.org/licenses/by/3.0/). 